\title{
Maternal Healthcare Faces Challenges in Uncertain Times
}

\author{
Madeline Kaplan \\ ${ }^{1}$ Georgetown University School of Medicine \\ Keywords: global health, pregnancy, covid-19 \\ https://doi.org/10.52504/001c.13649
}

Georgetown Medical Review

Vol. 4, Issue 1, 2020

\begin{abstract}
As the coronavirus pandemic progressed around the world, hospitals and healthcare settings were under unprecedented demand and stress. While many areas of medicine not related to treating COVID patients were put on the sidelines, obstetric patients still required checkups and hospital stays for labor and delivery. This article provides an overview of the experiences women faced while giving birth during this time, and the unique policies necessary to provide women with quality care and safe spaces to deliver in such strenuous times.
\end{abstract}

Vulnerable populations in any society are going to face a disproportionate burden in times of crisis. The coronavirus disease 2019 (COVID-19) pandemic is no different, and pregnant women are very vulnerable because they have unavoidable and regular interaction with hospitals. Obstetric patients occupy a unique space in this pandemic because it may be necessary for them to make frequent trips to a health care setting in the months leading up to their delivery, and most choose to deliver in a hospital. Furthermore, the delivery of a child is not a medical event that can be delayed past 40 weeks.

Around the world, hospitals are scrambling to come up with policies that provide protection against the virus to their staffers and patients, while trying to respect the choices of the mothers-to-be. On reviewing the current measures being taken by hospitals worldwide, along with written narratives from women who have given birth so far during the pandemic, it is clear that in times of chaos, as seen during this COVID-19 pandemic, it is necessary for hospitals to develop policies on how to properly deal with obstetric patients. Without strong policy regarding their treatment during a pandemic, pregnant women are likely at risk for higher maternal mortality rates, more complications after birth, and a greater risk of getting infected. In fact, the chaos surrounding COVID-19 has made many women turn towards the option of home birth, ${ }^{1} \mathrm{a}$ practice the American College of Obstetricians and Gynecologists describes as riskier for both mom and baby. ${ }^{2}$ The time for active policy making is now, as the pandemic wages on in many US cities and around the world.

There are 2 important tenets that need to be taken into consideration when discussing a new policy for delivery during a pandemic: testing and accompaniment by a partner. The first, and probably most obvious, tenet in policies should be universal testing. All around the country, hospitals are requiring coronavirus nasopharyngeal swabs for patients arriving to give birth. In early April of 2020, physicians from Columbia University Irving Medical Center in New York City wrote a letter describing how universal testing of 
obstetric patients has given them invaluable information regarding neonatal care, room assignments, and isolation practices, as well as the correct personal protective equipment required to care for each patient. ${ }^{3}$ It is clearly necessary to test women (and their partners) who are arriving to give birth; however, even more crucial than COVID-19 testing is making sure the tests can be analyzed in a short enough time period. Many hospitals across the country struggled to implement testing to all arriving obstetric patients because it was not clear that the test results would be ready before delivery. At Tufts Medical Center, the window for test results was about 12 hours, although the center has recently shortened that time to no more than 90 minutes for obstetric patients. ${ }^{4}$ Clearly, 12 hours is too long a wait time considering how quickly labor and delivery can progress, and while large hospitals in urban centers, such as Boston and New York, are able to acquire rapid tests, rural hospitals throughout the country face a scarcity of such resources.

Second, while testing on arrival is critical from a medical perspective, some expectant mothers in both the United States and around the world are struggling with the prospect of giving birth alone when they had not expected to. In Montreal, Canada, Jewish General Hospital announced that there would be no visitors or partners allowed in predelivery, delivery, or postdelivery recovery at any point during the woman's stay. The policy was announced after one woman's partner visited despite having symptoms of COVID-19 and subsequently infected 2 staff members. ${ }^{5}$ Similarly, NewYork-Presbyterian and Mount Sinai announced there would be no support people allowed in the delivery units. However, no more than 3 days later, Governor Andrew Cuomo announced that all hospitals in the state must allow for 1 person to accompany women through labor and delivery. ${ }^{6}$ The WHO recognizes the importance of a woman having support in the room during delivery aside from the nurses and physicians. ${ }^{7}$ Moreover, a recent study demonstrated that women who had support in the delivery room were more likely to have shorter labors, give birth to babies with lower Apgar scores, and feel more positively towards the experience as a whole. ${ }^{8}$

Not only is this vital for the mental health of the mother that she be allowed a personal support companion, but it can also be seen as vital to her physical health. Kotlar, of the Center of Excellence in Maternal and Child Health at Harvard, described a young first-time mother who went into labor during the pandemic and was told her doula could not accompany her into the hospital due to COVID-19 restrictions. Her primary concern about not having her doula with her was not the lack of emotional support, but rather she was concerned that the physicians would not listen to her alone because she was black. ${ }^{9}$ The current maternal mortality rate for black women in the United States is dismal (black women are 3-4 times more likely to die from a pregnancy- or delivery-related issue than white women ${ }^{10}$ ) and needs to be systematically addressed. This highlights the necessity of having a support person in the delivery space. 
Hospitals need to understand the complex and often varying reasons women seek to have partners alongside them during delivery, and it should be worked into every policy that each woman gets at least 1 support person. To ensure the safety of staff and patients against COVID-19 and simultaneously protect the rights of women giving birth, hospitals should test the partners on arrival and instruct patients and partners alike to quarantine in the days leading up to their delivery (when possible).

Furthermore, it is important to note that in many parts of the world, with high maternal mortality rates all year around, it is even more crucial to protect the rights of these mothers during a pandemic. Amnesty International ${ }^{11}$ has recently shown the hurdles that women in Zimbabwe face while trying to access maternal care during the COVID-19 pandemic. The report highlights that women are fearful of police brutality and jail time if they are caught outside of their houses during the COVID-19-related lockdown, so much so that they traveled to the hospital days before the lockdown went into place just to "sit and wait" until it was time to give birth. Other lockdown-related issues included pharmacies having altered hours, smaller clinics not being open for checkups, and many health care settings that are normally accessible to lowincome women and their children being closed until the pandemic ends. ${ }^{11}$ Maternal health care must be made a priority to ensure that women have access to safe birth practices and recovery options that ensure their health and that of their newborn. If not, we could see much larger mortality rates during a pandemic that are not directly caused by the virus or disease.

It is crucial that in a pandemic we as a medical community are as prepared as possible, that we protect our fellow health care workers and their families, and that ultimately, we help as many patients as we can. Additionally, patients who can continue their normal medical routines have a lot to offer in terms of understanding the larger progression of a novel virus like COVID-19. Interestingly, obstetric patients provided epidemiological insight into physicians dealing with the novel coronavirus in New York City. It was through the testing of pregnant women on arrival to the hospital that it was learned that $87.9 \%$ of positive test results were from asymptomatic individuals. ${ }^{1}$ However, it is unclear whether physiological immunosuppression during pregnancy systematically biases these results.

While rapid testing is necessary for immediate safety, obstetric patients provide data for epidemiologists that can be useful in dealing with similar events in the future: poor test availability and the need for clarity on how to resolve a pandemic. The data is a bonus for epidemiologists, but it still remains critical that we ensure that our vulnerable health populations are not further disenfranchised from good health care. In regard to pregnant women, this means rapid testing on arrival, adequate treatment and isolation practices if the patient is positive, allowing for a support individual to be present, and ensuring 
that postdelivery care is equally accessible for all patients. Moving forward, policy makers and hospitals alike have a duty to develop effective guidelines that recognize the vulnerabilities of these populations and strive to protect them. 


\section{REFERENCES}

1. Gammon K. Should you have a home birth because of coronavirus? New York Times. Published March. https://www.nytimes.com/2020/03/30/parenting/home-birth-coronavirus-hospital.html. Published March 30, 2020. Accessed May 11, 2020.

2. Committee on Obstetric Practice. Committee Opinion Number 697 on Planned Home Birth. August 2016. https://www.acog.org/clinical/clinical-guidance/committee-opinion/articles/2017/ 04/planned-home-birth.

3. Sutton D, Fuchs K, D’Alton M, Goffman D. Universal screening for SARS-CoV-2 in women admitted for delivery. NEngl J Med. 2020;382(22):2163-2164. doi:10.1056/nejmc2009316

4. Bebinger M. Major Boston hospitals are virus testing pregnant patients arriving to give birth. WBUR Updated April28, 2020. https://www.wbur.org/commonhealth/2020/04/28/ covid19-pregnant-universal-testing-mass-hospitals. Accessed May 7, 2020.

5. Mignacca F. With maternity ward off-limits to partners, a mother-to-be struggles with fear and uncertainty. Updated April5, 2020. https://www.cbc.ca/news/canada/montreal/jgh-maternitycoronavirus-rule-1.5522380. Accessed May 6, 2020.

6. Van Syckle K, Caron C. Women will not be forced to be alone when they are giving birth. New York Times. Published. https://www.nytimes.com/2020/03/28/parenting/nyc-coronavirushospitals-visitors-labor.html. Published March 28, 2020.

7. WHO International. Why having a companion during labour and childbirth may be better for you.https://www.who.int/reproductivehealth/companion-during-labour-childbirth/en/.

Published March 2019.

8. Bohren MA, Hofmeyr GJ, Sakala C, Fukuzawa RK, Cuthbert A. Continuous support for women during childbirth. Cochrane Database Syst Rev. 2017;7(7):CD003766. doi:10.1002/ 14651858.cd003766.pub6

9. Kotlar B. Amidst the COVID-19 pandemic, we must remember maternal health. Maternal Health Task Force. Published. https://www.mhtf.org/2020/04/18/amidst-the-covid-19-pandemicwe-must-remember-maternal-health/. Published April 18, 2020.

10. Creanga AA, Syverson C, Seed K, Callaghan WM. Pregnancy-related mortality in the United States, 2011-2013. Obstetrics छ Gynecology. 2017;130(2):366-373. doi:10.1097/ aog.0000000000002114

11. Chikwanda V. The devastating effects of COVID-19 on maternal health in Zimbabwe. Amnesty International. Published April. https://www.amnesty.org/en/latest/campaigns/2020/04/thedevastating-effects-of-covid19-on-maternal-health-in-zimbabwe/. Published April 29, 2020. 